\title{
COMPARISON BETWEEN TWO AND THREE PARAMETERS OF FATIGUE CRACK GROWTH MODELS IN AIRFRAME STRUCTURES
}

\author{
M.S. Wahab, Yu.M. Paramonov
}

Riga Technical University, Aviation Institute, Riga, Latvia. Lomonosova 1, Riga, LV-1019, Latvia E-mail: shujawahab@hotmail.com,rauprm@junik.lv Received 2510 2004, accepted 10062005

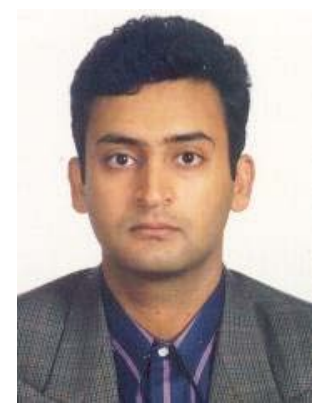

\begin{abstract}
Muhammad Shujauddin WAHAB, PhD Student Birth date: November 09, 1976 in Karachi (Pakistan)

Education: Master's degree, Aviation Institute, Riga Technical University, Latvia, 2004

Conferences: International Conference "Reliability and Statistics in Transportation and Communication (RelStat'04), Riga, 14 -15 October 2004, Latvia.

Sixth International Seminar on "Recent Research and Design Progress in Aeronautical Engineering and Its Influence on Education” Riga Technical University, Aviation Institute, Riga, 14 - 16 October 2004, Latvia. Address: Aviation Institute, Riga Technical University, Lomonosova Street 1, LV-1019, Riga, Latvia, Tel.: +371 7089950 .
\end{abstract}

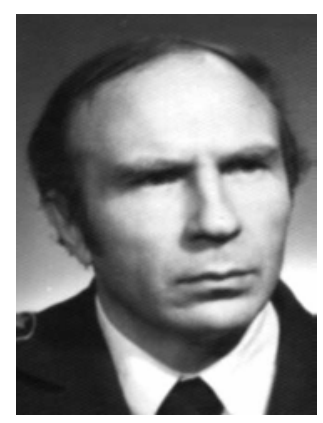

Yuri M. PARAMONOV, Prof Dr Habil Sc Eng

Date and place of birth: March 28, 1938, Leningrad.

Education: Riga Aviation Engineering Military High School, Mechanical Engineering Diploma with gold medal (1960). Riga Civil Aviation Eng. Institute, Doctor Sc. Eng. Degree (1965). Latvian Academy of Sciences, High Doctor Degree in Technical Cybernetics (1974). Riga Aviation University and Latvian Academy of Science, Doctor Habilitus Degree in Engineering (1993).

Fields of research: Reliability of technical systems; mathematical statistics; load, structure, and strength analysis of transport vehicles; information technology application (development of automated control systems).

Member of professional societies: American Statistical Association, Research Board of Advisors of the American Biografical Institute, Participation in 15 international conferences;

Publications: 145, including 9 monographs and textbooks.

Honours, awords: Honoured Scientist of Latvian Soviet Socialist Republic (1983); order: Honour Decoration (1971);

Medals: For Valiant Labour (1970), Labour Veteran (1985); Nomination as an International Man of the Year for 1997/98 by the International Biografical Centre of Cambridge.

Present position: Professor in Aircraft Theory and Structure Department of Aviation Institute of Riga Technical University, Lomonosova Street 1, Riga, LV-1019, Latvia, +(371)-2255394, + (371)-7 089966.

\begin{abstract}
Comparison of two and three parameters models of fatigue crack growth is discussed. For calculation of failure probability, the Monte Carlo (MC) method is used. The number of MC trials was 60. Multiple site fatigue damage specimens corroded to $5 \%$ to $6 \%$ average thickness loss and non-corroded specimens were used in the fatigue tests. As initial data, the result of these fatigue tests of corroded and non-corroded specimens are used. It is shown that at a small number of inspections there is a significant difference between probabilities of failure (fatigue crack is not discovered before specified life). But if the number of inspections is large enough, than the difference between considered models is negligible for both corroded and non-corroded specimens.
\end{abstract}

Key words: fatigue crack growth, corrosion medium, failure probability, inspection program and specified life.

\section{Introduction}

Fatigue crack growth analysis in the presence of corrosion is an important subject because it can degrade the structural integrity and damage tolerance of fatigue critical structural components in aging aircrafts [2]. Multiple site fatigue damage (MSD) in a longitudinal skin splice has been recognized as a major airworthiness problem. It had a very significant influence in the B747200 disaster in 2002 .
For fleet management, it is important to know the effects of corrosion in normal service on the durability and damage tolerance (DADT) characteristics of the fuselage. The DADT characteristic of any structure is defined by crack initiation and growth patterns, the critical crack scenarios that could develop, and the number of load cycles it takes for cracks to become detectable and then grow to a critical condition.

Crack development in a combined MSD and corrosion environment has characteristics that are quite different from and more stochastic than those related to a single crack situation. 
The probabilistic analysis methodologies should be as simple as possible while maintaining reasonable accuracy for predicting the failure probability of fatigue critical components. The objective of this paper is to compare the results obtained from the two and three parameter models of fatigue crack growth.

\section{Test program}

The MSD concept is illustrated by a generic lap splice version of the specimen clearly shown in Fig 1. A finite element model of the loop stress distribution in specimens is also shown. The concept is the use of bonded side straps to simulate the load transfer from cracked areas to surrounding structure that occurs on aircraft. The specimen shown is a $25.4 \mathrm{~cm}$ (10 in) wide version, designed to be representative of the longitudinal fuselage splices in some narrow body transport aircraft. The splice in the generic specimen comprises two sheets of $1.0 \mathrm{~mm}(0.04 \mathrm{in})$ thick 2024-T3 Alclad held by three rows of $4 \mathrm{~mm} \mathrm{(5/32} \mathrm{in)} \mathrm{diameter} \mathrm{20177-T4} \mathrm{rivets}$ (MS20426AD5-5) without adhesive, paint, or sealant. The rivet geometry results in a knife-edge countersink.

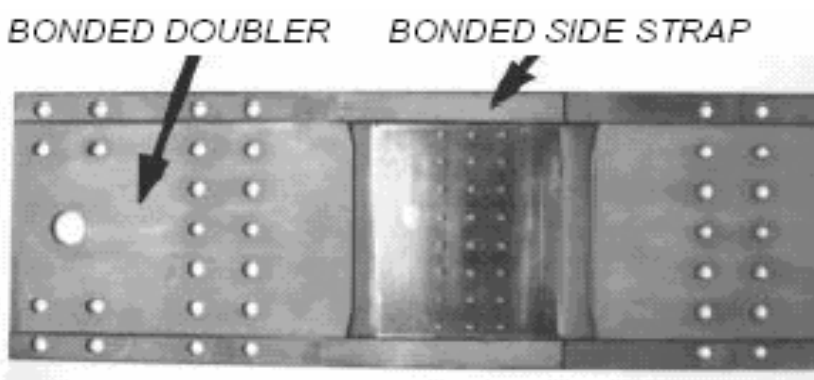

(a)

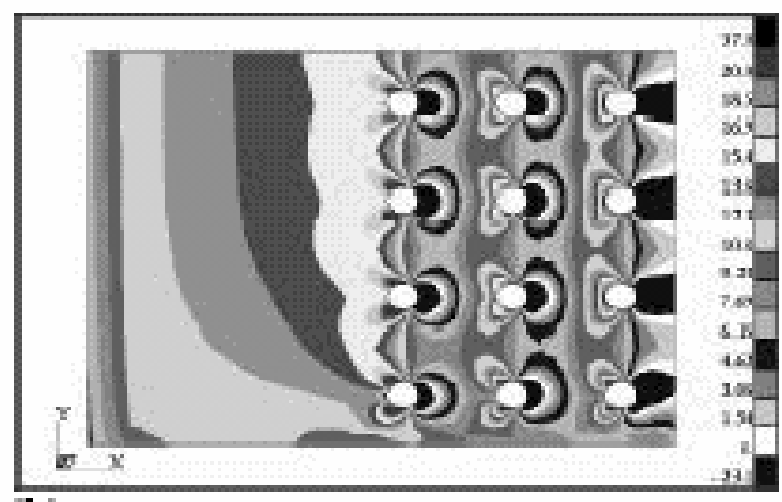

(b)

Fig 1. Illustration of MSD specimen (a) bonded doubler, (b) with a hoop stress distribution at faying surface by finite element prediction
There are altogether nine MSD specimens, out of which five are non-corroded and four are relatively heavily corroded. They all are fatigue tested. The four corroded MSD specimens (average thickness loss of between $5 \%$ and $6 \%$ ) were compared with the damage in a section of splice from a Boeing 727 aircraft. This section was naturally corroded to a comparable level during 48.665 flights over 24 years. So one flight is approximately equivalent to 4.266 cycles.

These specimens are listed in Table 1 along with their respective fatigue life at visible crack detection, first link up, and final failure.

Table 1. Fatigue life of MSD specimen

\begin{tabular}{|c|c|c|c|c|}
\hline \multicolumn{2}{|c|}{ Specimen \# } & \multicolumn{3}{|c|}{ Fatigue Life (Cycles) } \\
\hline & & $\begin{array}{l}1^{\text {st }} \\
\text { observed }\end{array}$ & $\begin{array}{l}1^{\text {st }} \\
\text { Linkup }\end{array}$ & $\begin{array}{l}\text { Final } \\
\text { failure }\end{array}$ \\
\hline \multirow{5}{*}{$\begin{array}{l}\text { Non- } \\
\text { corroded }\end{array}$} & Cgc-f38 & 387500 & 491711 & 501933 \\
\hline & Cgc-f46 & 314000 & 398908 & 403718 \\
\hline & Cgc-f51 & 304001 & 381378 & 392591 \\
\hline & Cgc-f60 & 290000 & 368650 & 378754 \\
\hline & Cgc-f61 & 368500 & 473397 & 481353 \\
\hline \multicolumn{4}{|c|}{ Average Final Failure } & 431670 \\
\hline \multirow{4}{*}{$\begin{array}{l}\text { Corroded } \\
\text { to } 5 \% \text { - } \\
6 \% \text { level }\end{array}$} & Cgc-cf34 & 160001 & & 222450 \\
\hline & Cgc-cf43 & 144000 & & 189074 \\
\hline & Cgc-cf45 & 104107 & & 177129 \\
\hline & Cgc-cf58 & 142000 & & 241909 \\
\hline \multicolumn{4}{|c|}{ Average Final Failure } & 207640 \\
\hline
\end{tabular}

The combination of corrosion and fatigue assumes that a corrosion/fatigue interaction occurs only in the context of pre-existing corrosion and in a dry splice. This is a reasonable approximation for two reasons. First, teardown of aircraft splices and evidence indicates that substantial corrosion often exists without any associated fatigue cracking. Second, the highest in-service loads occur when any moisture in the splice is likely to have frozen.

\section{Failure characteristics}

The test data for the crack growth history of the two specimen groups are shown in Figure 2 and 3 . In the corroded specimens, the overall crack growth rate was relatively stable during the whole growth period similar to the growth progression of a single crack. On the other hand, in the non-corroded specimens, first linkup occurred at an aggregate crack length of about $50.8 \mathrm{~mm}$ ( 2 in). Subsequent crack growth was relatively fast and produced a pronounced knee in the growth curve. 


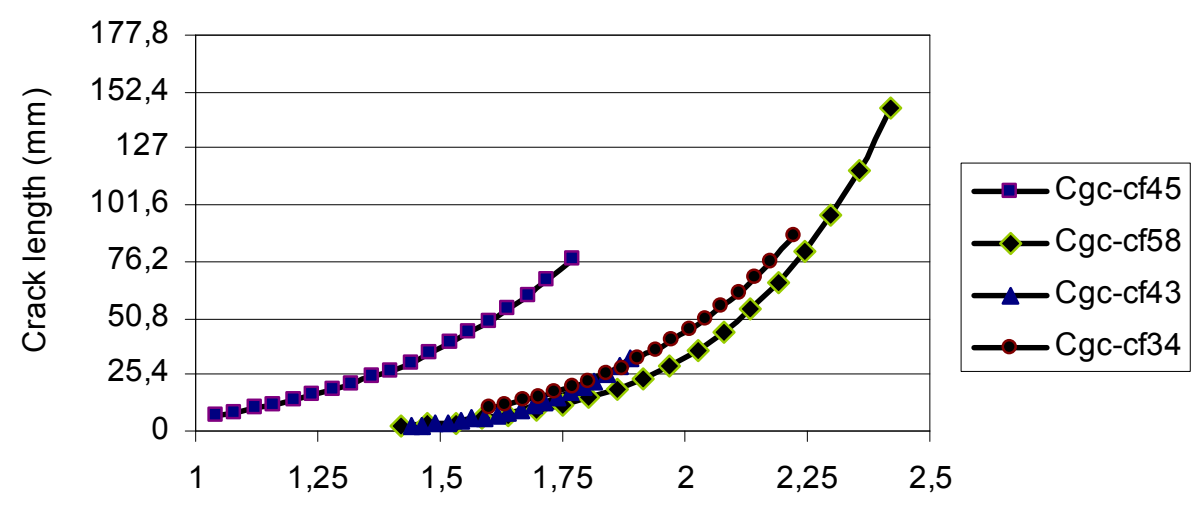

Number of load cycles $\left(x 10^{\wedge} 5\right)$

Fig 2. Crack growth history data of corroded specimens

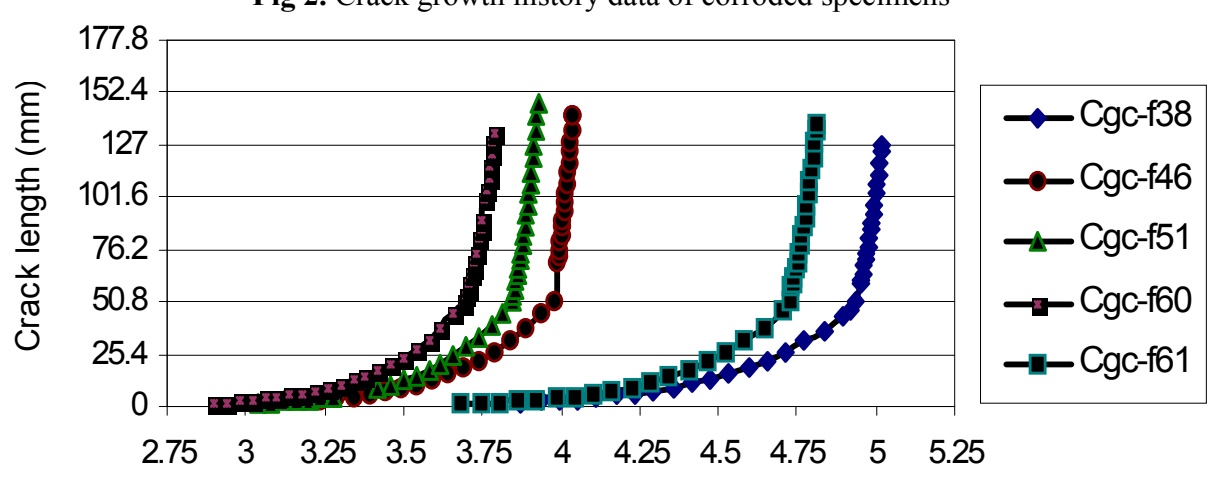

Number of load cycles (x10^5)

Fig 3. Crack growth history data of non-corroded specimens

With the above observation, the total service life of a specimen is divided into two or three stages. For noncorroded specimens, the total fatigue life, $\mathrm{N}_{t}$, is divided into three parts: life to visible cracks or visible damage starting life, $\mathrm{N}_{\mathrm{s}}$, growth life before linkup, $\mathrm{N}_{\mathrm{g} 1}$, and growth life after linkup, $\mathrm{N}_{\mathrm{g} 2}$, that follow $\mathrm{N}_{\mathrm{t}}=\mathrm{N}_{\mathrm{s}}+\mathrm{N}_{\mathrm{g} 1}+$ $\mathrm{N}_{\mathrm{g} 2}$. For the corroded specimens to the $5 \%$ to $6 \%$ level, a single stage with growth life $\mathrm{N}_{\mathrm{s}}$, is used for the whole growth period because of their relatively stable growth behavior, and the total fatigue life is $\mathrm{N}_{\mathrm{t}}=\mathrm{N}_{\mathrm{s}}+\mathrm{N}_{\mathrm{g}}$. The visible damage starting life is the number of load cycles at which the first crack was observed and the total life of a specimen is when the final failure occurred. The growth life is the difference between the total life and the damage starting life $\mathrm{N}_{\mathrm{g}}=\mathrm{N}_{\mathrm{t}}-\mathrm{N}_{\mathrm{s}}$.

\section{Determination of fatigue crack growth function parameters}

Following Yang's paper, it is assumed that fatigue crack growth of some items of airframe is defined by the formula $[4,3,1]$ :

$a(t)=a(o) /\left(1-\mu(a(o))^{\mu} Q t\right)^{1 / \mu}$

Where,

$$
\mu=m / 2-1
$$

The parameter $\mu$ depends on the characteristics of the material

A (0) - equivalent beginning size of a crack

In this paper we consider two cases when $m \neq 2$ and when $\mathrm{m}=2$.

\subsection{Three fatigue crack growth function parameters $(m \neq 2)$}

Processing of data for crack growth during fatigue experiments using the least square method, we can get estimates of the parameters of this equation.

Results of processing four fatigue crack growth data for corroded specimens at 5\%-6\% level are given in Table 2.

Table 2. Fatigue crack growth parameters for corroded specimens at $5 \%-6 \%$ level

\begin{tabular}{|c|c|c|c|c|}
\hline $\begin{array}{c}\text { Serial } \\
\text { No }\end{array}$ & Specimen \# & $\mu$ & $\mathrm{b}_{\mathrm{o}}=\ln \mathrm{Q}$ & $\mathrm{A}(0)$ \\
\hline 1. & Cgc-cf34 & -0.15424 & -9.75393 & $2.37 \mathrm{E}-19$ \\
\hline 2. & Cgc-cf43 & -0.10353 & -9.52048 & $1.48 \mathrm{E}-27$ \\
\hline 3. & Cgc-cf45 & -0.22511 & -9.61464 & $4.51 \mathrm{E}-13$ \\
\hline 4. & Cgc-cf58 & -0.12758 & -9.70537 & $1.63 \mathrm{E}-18$ \\
\hline \multicolumn{2}{|r|}{ Average } & -0.15262 & -9.6486 & $1.13 \mathrm{E}-13$ \\
\hline \multicolumn{2}{|c|}{ Standard Deviation } & 0.052581 & 0.103096 & $2.26 \mathrm{E}-13$ \\
\hline
\end{tabular}


Results of processing five fatigue crack growth data for non-corroded specimens are given in Table 3.

Table 3. Fatigue crack growth parameters for non-corroded specimens

\begin{tabular}{|l|c|c|c|c|}
\hline $\begin{array}{l}\text { Serial } \\
\text { No. }\end{array}$ & Specimen \# & $\mu$ & $\mathrm{b}_{\mathrm{o}}=\ln \mathrm{Q}$ & $\mathrm{a}(0)$ \\
\hline 1. & Cgc-f38 & 0.432273 & -11.2323 & 0.079004 \\
\hline 2. & Cgc-f46 & 0.44934 & -11.0738 & 0.091935 \\
\hline 3. & Cgc-f51 & 0.334914 & -10.6355 & 0.02707 \\
\hline 4. & Cgc-f60 & 0.249426 & -10.5026 & 0.014186 \\
\hline 5. & Cgc-f61 & 0.322694 & -10.7252 & 0.018577 \\
\hline \multicolumn{2}{|c|}{ Average } & 0.35773 & -10.8339 & 0.046155 \\
\hline \multicolumn{2}{|l}{ Standard Deviation } & 0.082805 & 0.307091 & 0.036475 \\
\hline
\end{tabular}

In the simulation of a process of fatigue crack inspection, it is assumed that some inspection technology is characterized by two values: $a_{d}$ and $w_{i} ; a_{d}$ is the minimum size of a detectable crack and $\mathrm{w}$ is interpreted as the probability that the earlier scheduled inspection will be made with the required accuracy. Service time when crack becomes detectable $t_{d}$ and service time to fatigue failure $t_{\mathrm{f}}$ are defined below:

$t_{d}=\frac{C_{d}}{Q} \quad t_{f}=\frac{C_{f}}{Q}$

We consider, that $t_{d}$ and $t_{f}$ are functions of the random variable $\mathrm{Q}$.

$\mathrm{C}_{\mathrm{d}}$ is the constant for both non-corroded and corroded specimens with different a (0).

$C_{d}=\frac{1-\left(\frac{a(o)}{a_{d}}\right)^{\mu}}{\mu(a(o))^{\mu}}$

Where $a_{d}$ is the initial detectable size of the fatigue crack.

$\mathrm{C}_{\mathrm{f}}$ is the constant for the case when $\mu$ is negative. It takes place for the corroded specimens

$$
C_{f}=\left[\frac{\left(\left(K_{c} / \sigma_{\max }\right)^{2} * 1 / \pi\right)^{\gamma}-(a(o))^{\gamma}}{\gamma}\right]
$$

$\mathrm{C}_{\mathrm{f}}$ is the constant for the case when $\mu$ is positive. It takes place for the non-corroded specimens.

$$
C_{f}=\frac{1-\left(\frac{a(o)}{\frac{K_{c}{ }^{2}}{\sigma_{\max }{ }^{2} \pi}}\right)^{\mu}}{\mu a(o)^{\mu}}
$$

\subsection{Two fatigue crack growth function parameters $(m=2)$}

Using the exponential model, the fatigue crack growth function parameters are: $a(0)$ - equivalent beginning size of the crack and $Q$ - random variable. They are being evaluated. In this case, $\mu=0$, and Yang's formula will be as follows:

$a(n)=a(0) * e^{Q t}$

$\ln (a(n))=\ln (a(0))+Q t$

$\mathrm{Y}=\mathrm{b}_{0}+\mathrm{b}_{1} * \mathrm{X}$

$\mathrm{b}_{0}=\ln \left(\mathrm{a}(0) \mathrm{b} 1=\mathrm{Q} \quad \ln \mathrm{b}_{1}=\ln \mathrm{Q}\right.$

$t=\frac{\ln (a(n))-\ln (a(0))}{Q}$

$t=\left(\ln \frac{a(n)}{a(0)}\right) * \frac{1}{Q}$

So time for failure:

$t_{f}=\ln \frac{a_{f}}{a(0)} * \frac{1}{Q}$

So time when fatigue crack becomes detectable:

$t_{d}=\ln \frac{a_{d}}{a(0)} * \frac{1}{Q}$

$\mathrm{C}_{\mathrm{f}}, \mathrm{C}_{\mathrm{d}}$ - constants for the corroded and non-corroded specimens:

$C_{f}=\ln \frac{a_{f}}{a(0)} \quad C_{d}=\ln \frac{a_{d}}{a(0)}$

For the corroded specimens averages and the standard deviation for $\ln \mathrm{Q}$ and a (0) are given in Table 4.

Table 4. Calculations of averages and STD for $\ln Q$ and a (0)

\begin{tabular}{|c|c|c|c|c|c|}
\hline $\mathrm{n}$ & SPECIMEN & $\mathrm{b}_{0}=\ln \mathrm{a}(0)$ & $\operatorname{expb}_{0}=\mathrm{a}(0)$ & $\mathrm{b}_{1}=\mathrm{Q}$ & $\ln \mathrm{b} 1=\ln \mathrm{Q}$ \\
\hline 1 & Cgc-cf34 & -3.0351411 & 0.048068 & $3.3973 \mathrm{E}-05$ & -10.28995215 \\
\hline 2 & Cgc-cf43 & -7.4150251 & 0.000602 & $5.8011 \mathrm{E}-05$ & -9.75486935 \\
\hline 3 & Cgc-cf45 & -1.2249512 & 0.293772 & $3.1974 \mathrm{E}-05$ & -10.35057759 \\
\hline 4 & Cgc-cf58 & -4.8357248 & 0.007941 & $4.1176 \mathrm{E}-05$ & -10.09765688 \\
\hline & AVERAGE & -4.1277105 & 0.087596 & $4.1284 \mathrm{E}-05$ & -10.12326399 \\
\hline & ST.DEV & 2.64117655 & 0.139025 & $1.1831 \mathrm{E}-05$ & 0.268220526 \\
\hline
\end{tabular}

For the non-corroded specimens, averages and the standard deviation for $\ln \mathrm{Q}$ and a (0) are given in Table 5. 
Table 5. Calculations of averages and STD for $\ln \mathrm{Q}$ and a (0)

\begin{tabular}{|c|c|c|c|c|c|}
\hline $\mathrm{n}$ & SPECIMEN & $\mathrm{b}_{0}=\ln \mathrm{a}(0)$ & $\operatorname{expb}_{0}=\mathrm{a}(0)$ & $\mathrm{b}_{1}=\mathrm{Q}$ & $\ln \mathrm{b} 1=\ln \mathrm{Q}$ \\
\hline 1 & Cgc-f38 & -12.53839 & $3.5863 \mathrm{E}-06$ & $3.3935 \mathrm{E}-05$ & -10.29107816 \\
\hline 2 & Cgc-f46 & -13.1968110 & $1.85651 \mathrm{E}-06$ & $4.4135 \mathrm{E}-05$ & -10.02824832 \\
\hline 3 & Cgc-f51 & -14.030765 & $8.06336 \mathrm{E}-07$ & $4.7497 \mathrm{E}-05$ & -9.95484854 \\
\hline 4 & Cgc-f60 & -12.793649 & $2.77836 \mathrm{E}-06$ & $4.5899 \mathrm{E}-05$ & -9.989064861 \\
\hline 5 & Cgc-f61 & -14.3899557 & $5.63017 \mathrm{E}-07$ & $3.9417 \mathrm{E}-05$ & -10.14131679 \\
\hline & AVERAGE & -13.389914 & $1.9181 \mathrm{E}-06$ & $4.2177 \mathrm{E}-05$ & -10.08091133 \\
\hline & ST. DEV & 0.79509219 & $1.28443 \mathrm{E}-06$ & $5.5124 \mathrm{E}-06$ & 0.136857506 \\
\hline
\end{tabular}

Bar chart of crack undetectable and crack detectable time periods (CUCDTP) in both cases are shown in Fig 4 and 5.

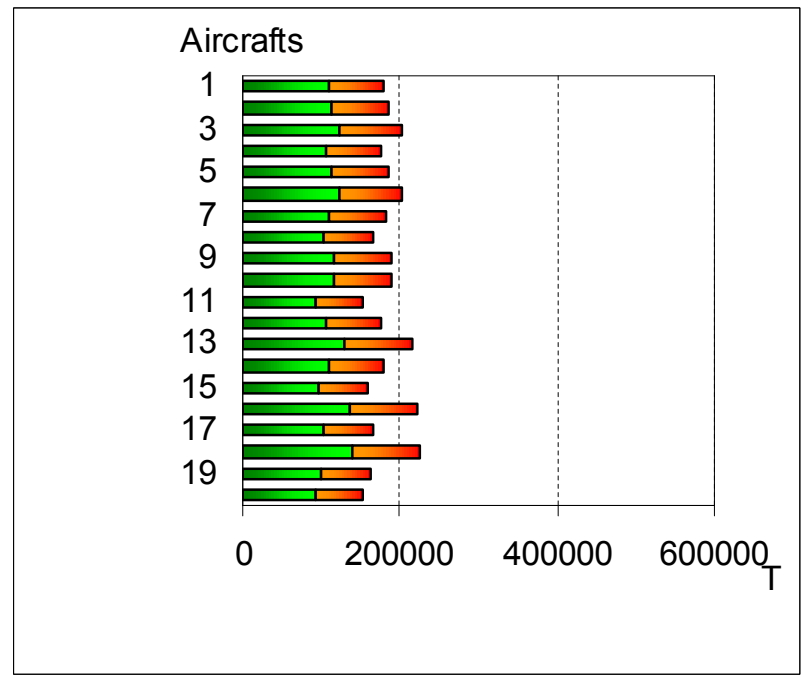

Fig 4. Bar chart of CUCDTP for the corroded specimens at $5 \%$ and $6 \%$ level

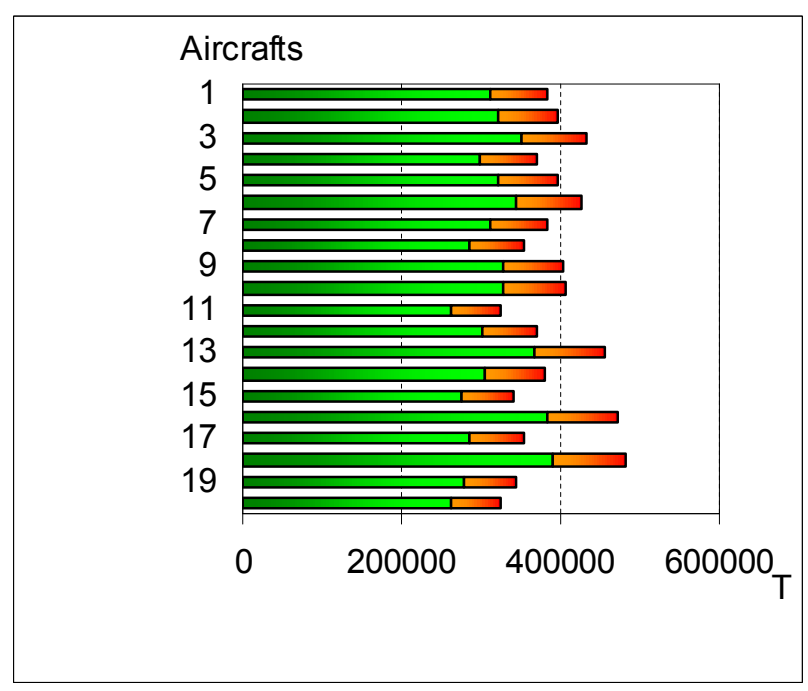

Fig 5. Bar chart of CUCDTP for the non-corroded specimens

\section{Interval between inspection and estimation of fatigue failure probability}

If all $\Delta_{\mathrm{i}}$ are equal, than:

$\Delta=\frac{t_{S L}}{(n+1)}$

Where $t_{S L}$ is the specified life of an aircraft $n$ is the number of inspections.

If we use the Monte Carlo (MC) method, then the failure probability in the interval $\left(t_{d}, t_{f}\right){ }_{j}$ with $r_{j}$ inspections on the $j$-th airplane is defined by the formula:

$$
\hat{p}_{f 1 j}=(1-w)^{r_{j}}
$$

$w$ is the probability that inspections will be made with the required accuracy

Then for $\mathrm{N}$ airplanes (or for $\mathrm{N}$ Monte Carlo trials), the mean failure probability $\left(P_{f}\right)$ wills the equal:

$\hat{p}_{f}=\frac{1}{N} \sum_{j=1}^{N} P_{f 1 j}$

Relevant curves $\mathrm{P}_{\mathrm{f}}=\mathrm{P}_{\mathrm{f}}(\Delta)$ and $\mathrm{P}_{\mathrm{f}}=\mathrm{P}_{\mathrm{f}}(\mathrm{n})$ in both the cases when $\mathrm{m} \neq 2$ and $\mathrm{m}=2$ for the corroded and non-corroded specimens are shown in Fig. $6-11$.

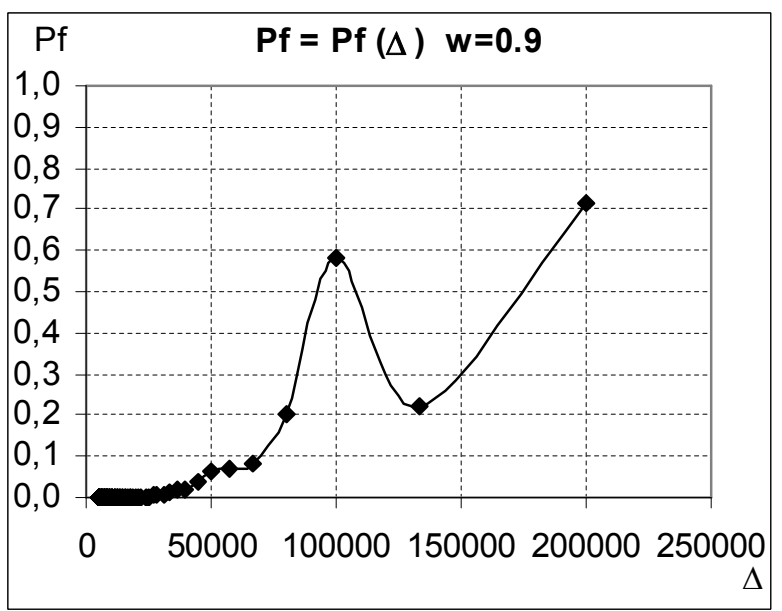

Fig 6. Failure probability in the case of $m \neq 2$ for the corroded specimens with specified life $=400000$ cycles 


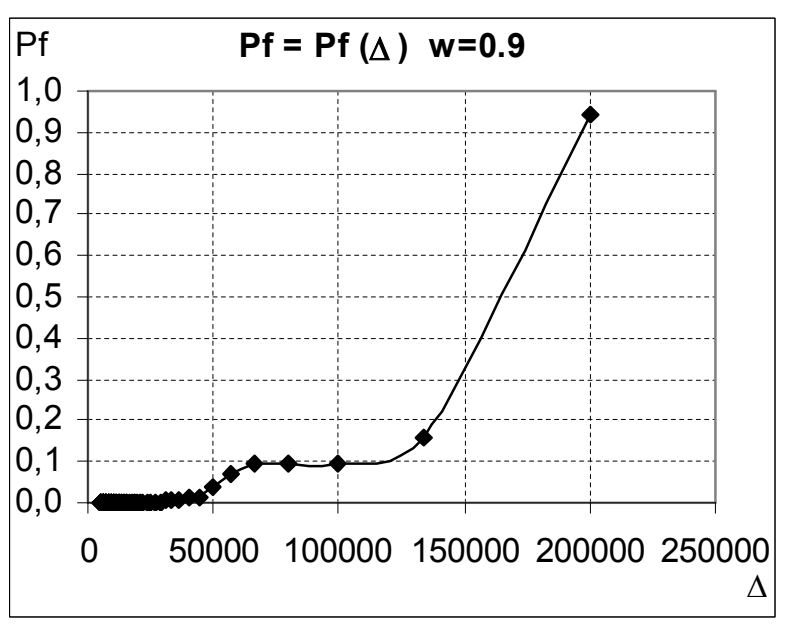

Fig 7. Failure probability in the case of $m=2$ for the corroded specimens with specified life $=400000$ cycles

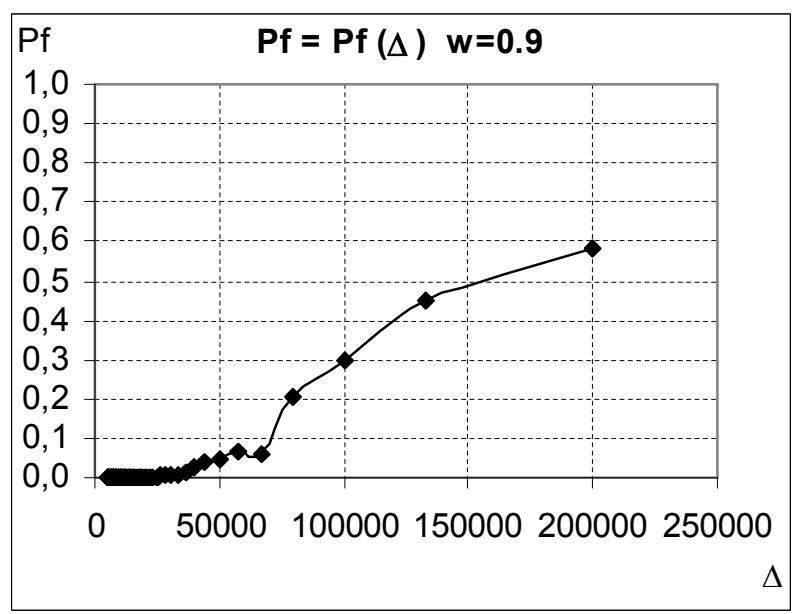

Fig 8. Failure probability in the case of $m \neq 2$ for the noncorroded specimens with specified life $=400000$ cycles

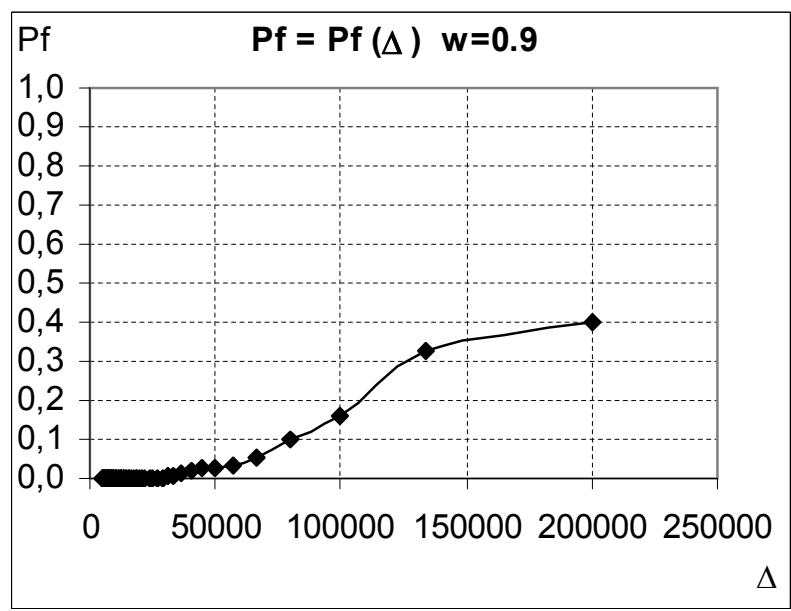

Fig 9. Failure probability in the case of $m=2$ for the noncorroded specimens with specified life $=400000$ cycles

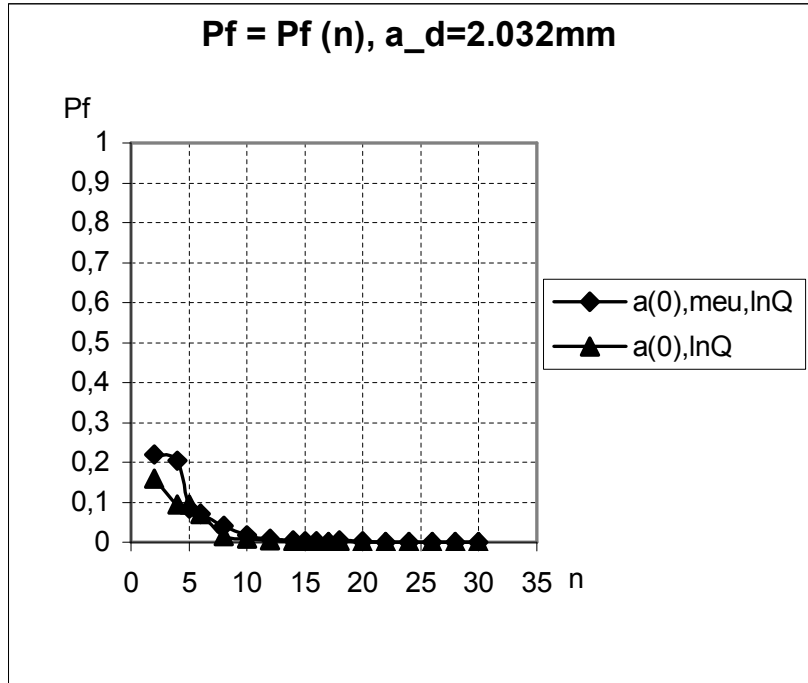

Fig 10. Failure probability in both the cases when $m \neq 2$ and $\mathrm{m}=2$ for the corroded specimens with specified life $=400000$ cycles

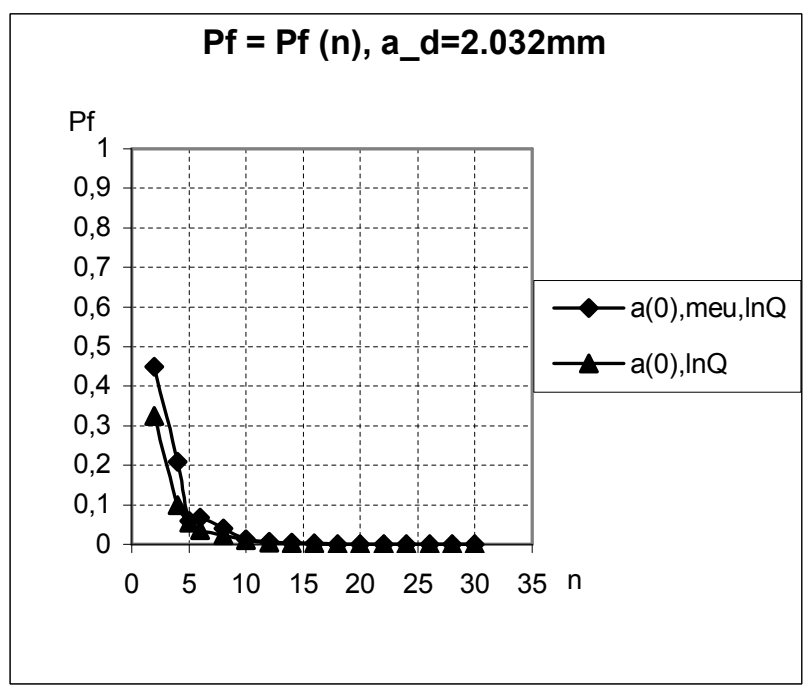

Fig 11. Failure probability in both the cases when $m \neq 2$ and $\mathrm{m}=2$ for the non-corroded specimens with specified life $=$ 400000 cycles

\section{Conclusions}

1. With the small number of inspections, it is observed that there is a significant difference between the probability of failures for both the models being analyzed on the corroded and noncorroded specimens at the specified life of 400000 cycles.

2. With the small value of the probability of failure, there is a very small difference between the compared models being used on the corroded and non-corroded specimens at the same specified life of to 400000 cycles. 


\section{Nomenclature}

a (t) =Fatigue crack size at time t;

a (0) =Equivalent beginning size of the crack;

$\Delta \quad=$ Interval between inspections;

$\mathrm{K}_{\mathrm{c}} \quad=$ Critical value of stress intensity factor;

$t_{d} \quad=$ Time when the fatigue crack is detectable;

$\mathrm{t}_{\mathrm{f}} \quad=$ Time when there is a structural failure;

$\mathrm{P}_{\mathrm{f}} \quad=$ Probability of failure;

$\mathrm{m}, \ln \mathrm{Q}=$ Crack growth function parameters;

$\mu \quad=$ Depends on the material characteristics;

w $\quad=$ Is the probability that inspections will be

w made with required accuracy;

$\mathrm{n} \quad=$ Number of inspections;

$\mathrm{Q} \quad=$ Parameter representing crack growth speed;

$\mathrm{C}_{\mathrm{d}}, \mathrm{C}_{\mathrm{f}}=$ Constants;

$\sigma_{\max } \quad=$ Maximum stress in flight;

$\mathrm{t}_{\mathrm{SL}} \quad=$ Specified life of an aircraft;

$t_{d}, t_{f}=$ Functions of random variables $Q$;

\section{References}

1. Wahab M.S., Paramonov Yu.M. Influence of corrosion on the required number of airframe inspections // Proceedings of the International Conference "Reliability and Statistics in Transportation and Communication (RelStat'03) 16 - 17 October 2003. - Riga: Transport and Telecommunication Institute, 2004. - Vol 1. - P. 180-190.

2. Xiong Y., Eastaugh G., Shi G. Probabilistic failure analysis of fuselage splice joints with multiple site fatigue damage and corrosion // Proceedings of the Twentieth ICAF Symposium "Structural Integrity for the next Millennium". Bellevue, Washington, USA, 14-16 July 1999, /Ed. by R.M Bader and J.L Rudd. - Washington, 1999. - 2 Volumes. - 1232 p.

3. Yang J.N. Statistical crack growth in durability and damage tolerant analysis // Proceedings of the $22^{\text {nd }}$ Conference of Structures, Structural Dynamics and Materials. - 1980. - P. 38-49.

4. Парамонов Ю.М., Кузнецов В.П. Живучесть авиационных конструкции. Оценка эффективности эксплуатации по состоянию. МУ. По выполнению самостоятельной роботы. - 1990. - 24 с. 